\title{
Lemming-Food Plant Interactions, Density Effects, and Cyclic Dynamics on the Siberian Tundra
}

\author{
SAM ERLINGE,${ }^{1,2}$ DENNIS HASSELQUIST, ${ }^{1}$ GÖRAN HÖGSTEDT, ${ }^{3}$ TARALD SELDAL, ${ }^{4}$ PETER FRODIN \\ and MIKAEL SVENSSON ${ }^{6}$
}

(Received 9 November 2010; accepted in revised form 12 April 2011)

\begin{abstract}
Theory predicts that trophic interactions can produce cyclic dynamics of microtine rodents, but that in addition, social interactions are necessary to create the cyclicity. We tested the induced defence hypothesis as a component driving multiannual cycles by analyzing data on Siberian lemming (Lemmus sibiricus Kerr) populations and the levels of trypsin inhibitors (TI) and free proteins (SPP) in their food plants. We collected data at 12 sites along the Palaearctic tundra coast in 1994 and correlated these measures with lemming density and cycle phase. A negative correlation between lemming density and TI/ SPP in Carex was found at the 12 sites. Cycle phase tended to correlate significantly with TI/SPP, and plants being grazed by lemmings respond with some delay. Mass of pancreas, the organ producing proteolytic enzymes, co-varied negatively with TI/SPP. These findings are in accord with predictions from the induced defence hypothesis. In contrast, reproductive effort did not conform to the predictions but co-varied strongly with density. Data are in accord with theory predicting that, in addition to trophic interactions, some self-regulation is necessary to create cyclic dynamics. Our data show that the plant defence hypothesis alone is not a sufficient explanation for the cyclicity. Several factors interact, including predation, food quality (including induced defence chemicals), and intra-specific competition.
\end{abstract}

Key words: lemming, cyclic dynamics, lemming-food plant interactions, density effect, Siberian tundra

RÉSUMÉ. En théorie, les interactions trophiques peuvent produire une dynamique cyclique de rongeurs microtinés, mais en plus de cela, il faut des interactions sociales pour donner lieu à la cyclicité. Nous avons mis à l'épreuve l'hypothèse induite de défense en tant que composante intégrale des cycles multi-annuels en analysant les données relatives aux populations de lemming brun (Lemmus sibiricus Kerr) et les taux d'inhibiteurs de la trypsine (TI) et de protéines libres (SPP) se trouvant dans leur nourriture végétale. Nous avons recueilli des données à 12 emplacements le long de la côte paléarctique des toundras en 1994 et avons corrélé ces mesures à la densité des lemmings ainsi qu'à la phase du cycle. Une corrélation négative entre la densité des lemmings et TI/SPP dans Carex a été trouvée à 12 emplacements. La phase du cycle avait tendance à donner une corrélation significative avec TI/SPP, et les végétaux faisant l'objet d'un pâturage par les lemmings réagissaient avec un certain retard. Les masses de pancréas, soit l'organe producteur des enzymes protéolytiques, co-variait négativement avec TI/SPP. Ces constatations cadrent avec les prédictions émanant de l'hypothèse induite de défense. Par contre, les efforts de reproduction ne se conformaient pas aux prédictions mais co-variaient fortement en fonction de la densité. Les données sont en accord avec la théorie prédisant qu'en plus des interactions trophiques, il faut une certaine autorégulation pour créer une dynamique cyclique. Nos données montrent qu'à elle seule, l'hypothèse de défense des végétaux ne constitue pas une explication suffisante à la cyclicité. Plusieurs facteurs entrent en interaction, dont la prédation, la qualité de la nourriture (ce qui comprend les produits chimiques induits de la défense) et la compétition intraspécifique.

Mots clés : lemming, dynamique cyclique, interactions entre les lemmings et les végétaux alimentaires, effet de la densité, toundra de la Sibérie

Traduit pour la revue Arctic par Nicole Giguère.

\footnotetext{
${ }^{1}$ Department of Animal Ecology, Lund University, S-223 62 Lund, Sweden

${ }^{2}$ Corresponding author: sam.erlinge:@zooekol.lu.se

${ }^{3}$ University of Bergen, Department of Zoology, Allégaten 41, N-5007 Bergen, Norway

${ }^{4}$ Present address: Høgskulen i Sogn og Fjordane, Postboks 133, N-6851 Sogndal, Norway

${ }^{5}$ Department of Earth \& Ecosystem Sciences, Lund University, Sölvegatan 12, S-223 62, Lund, Sweden

${ }^{6}$ Swedish Species Information Centre, Box 7007, S-750 07 Uppsala, Sweden

(C) The Arctic Institute of North America
} 


\section{INTRODUCTION}

Microtine rodents (voles and lemmings) in boreal and Arctic areas generally show cyclic population dynamics with peak densities at 3-4 year intervals. Many hypotheses have been proposed to explain this multiannual cyclic pattern (e.g., Krebs and Myers, 1974; Stenseth and Ims, 1993; Batzli, 1996; Hörnfeldt, 2004; Krebs, 2011), but no one theory has been universally accepted.

Stenseth et al. (1996) made an extensive review of current ecological information on periodically fluctuating microtine populations. When modeling cyclic dynamics from available long-term studies, they predicted that, in addition to trophic interactions, some self-regulation is necessary to create cyclic dynamics.

Examining trophic interactions, Krebs et al. (2003) described the trophic dynamics of the Canadian Arctic from extensive field data and found the system to be largely top-down for small and mid-sized herbivores. The flow of energy from small herbivores to predators is so large that herbivores have relatively little impact on the plants.

Angerbjörn et al. (1999) examined arctic fox (Alopex lagopus L.) predation on Siberian lemmings and suggested that the foxes, as resident specialist predators, could increase the amplitude and period length of the lemming cycle.

Some experimental studies give support to the hypothesis that predation, especially by small rodent specialists, drives the cyclic pattern (Korpimäki and Norrdahl, 1998; Klemola et al., 2000a; Korpimäki et al., 2002). A long-term field study on a cyclic population of collared lemming in Greenland suggested that a delayed numerical response of stoats (Mustela erminea L.) caused a cyclic pattern (Gilg et al., 2003). However, another experimental study manipulating weasel (Mustela nivalis L.) predation gave no conclusive evidence either against or for the specialist predation hypothesis (Sundell, 2002), and Graham and Lambin (2002) found that removal of weasels had no decisive effect on the cyclic decline of an experimental vole population.

Modeling of herbivore-plant interactions has suggested that food availability could account for the cyclic dynamics, at least in some populations (Turchin and Batzli, 2001). Studies on the effect of supplemental feeding have shown that it increased growth, survival, and reproduction, but in no case did it prevent the population decline (reviewed by Stenseth and Ims, 1993). Food quality has received less attention, but studies have addressed phenols, N, P, Ca, and $\mathrm{K}$, none of which seem to co-vary with rodent density (Jonasson et al., 1986; Lindroth and Batzli, 1986; Laine and Henttonen, 1987; Oksanen et al., 1987). Food plants can contain catechins. These are compounds of defensive plant secondary metabolites that belong to the tannin group (phenols) and are thought to affect the foraging of lemmings (Berg, 2003).

Proteinase inhibitors (PI), which are well known as defense agents in plant-insect interactions (Karban and Baldwin, 1997), correlated significantly with density of Norwegian lemmings (Lemmus norvegicus L.) (Seldal et al., 1994). PIs are produced in response to grazing and reduce the action of the herbivore's proteolytic enzymes (Seldal, 1994). High PI levels, as caused by grazing, may lead to a lack of protein for the herbivore, which in turn has negative effects on its prospects of growth, reproduction, and survival (Seldal, 1994). Such induced plant defence therefore has the potential to determine microtine cycles (Seldahl et al., 1994).

We report here on tests of five predictions from the hypothesis that trypsin inhibitors (TI), by inhibiting proteinase activity, negatively affect the density, life history, and pancreas size of Siberian lemmings. Specifically, after considering TI in plants consumed by the lemmings, we used correlational studies of data collected from 12 lemming populations on the Siberian tundra in 1994 to test these five predictions:

1. If there are delayed density-dependent effects (Hörnfeldt, 1994; Seldal, 1994), then the cyclic phases, arranged from low, via increasing, peak, and decreasing densities to crashed populations, should be associated with increasing level of TI in food plants (Seldal, 1994). Moreover, we expect no relationship or a negative relationship between TI and current lemming density (Seldahl, 1994).

2. If increased exposure to TI causes pancreatic hypertrophy (Seldal, 1994), then we predict a positive correlation between pancreas mass as a proportion of body mass and TI levels.

3. If TI has a direct negative effect on reproduction, then we predict a negative correlation between TI levels in food plants and the proportion of pregnant females, as well as the number of embryos per female.

4. If there are competitive interactions and reduced reproductive effort at high TI, then we expect a negative correlation between the proportion of young lemmings and TI levels.

Models based on the hypothesis that trophic interactions cause cyclic dynamics tend to focus on energy flow in ecosystems: either top-down processes (from predators via herbivores to plants) or bottom-up processes (from plants via herbivores to predators). Such models do not consider demographic mechanisms that could influence these processes. In contrast, in models based on a self-regulation hypothesis, these mechanisms are basic elements. From such a hypothesis, we predict that an intrinsic factor should be included when modeling the cyclic dynamics of arctic lemmings.

5. If intrinsic regulation is at work, then we predict a negative correlation between female reproductive activity and lemming density.

\section{MATERIALS AND METHODS}

In the summer of 1994, during a ship-borne expedition along the Palaearctic tundra over a vast region from the 
Kola Peninsula to Wrangel Island (Danell et al., 1999), we examined populations of Siberian lemmings. Their population dynamics had previously been found to be cyclic, with peak numbers every three or four years (Chernyavskii and Tkachev, 1982). We obtained extensive data at 12 places along the Siberian tundra and were fortunate to find these populations in different phases of the lemming cycle (Erlinge et al., 1999). The demographic analyses were based on information on current and previous lemming densities combined with the age profile of the populations.

\section{Measuring Lemming Density}

Lemming density was measured by means of snap-traps according to a standardized program based on the "small quadrat method" (Myllymäki et al., 1971). At each study site, 20 quadrats $(15 \times 15 \mathrm{~m})$ were established, each with 12 traps (three in each corner of the quadrat). The 20 quadrats were placed at about $60 \mathrm{~m}$ intervals along a transect of about $1300 \mathrm{~m}$. Traps were put out in habitats representative of a much larger area, in which lemming predators were censused. The 240 traps were checked every 8 hours, and trapping was carried out for at least 24 hours at each site. The number of captured Siberian lemmings per 100 trapdays was used as an index of population density. Altogether, 607 lemmings were captured (from 3 to 112 per site). In addition to lemmings trapped in the standard 240 traps at each site, the total also included lemmings captured by hand and in some extra traps set out at favourite places. The density index, which is based on our standardized trapping program and thus more comparable between the sites, varied between 0 and 29. For dates and number of lemmings captured at each site, see Erlinge et al. (1999).

\section{Phase and Age Determination}

At each of 12 field sites (Fig. 1), the phase of the lemming cycle was determined using demographic and dendrochronological methods (Erlinge et al., 1999). At each site, we recorded the amount of fresh and old lemming feces along lemming runways. We judged previous abundance from the age structure of the present populations and from dendrochronological data (Danell et al., 1981, 1995, 1999). Individual lemmings were aged using eye lens mass (Erlinge et al., 1999). We considered three age categories: juveniles born in the current summer $(<4$ months old $)$, young adults born the previous winter, and old adults born earlier than the previous winter.

A population in the increase phase is expected to have a medium current density and indications of low past density. The age profile is dominated by younger cohorts (Boonstra, 1994). A peak-phase population is expected to have a high density and a relatively high frequency of older individuals (Boonstra, 1994). A population in the decline phase should have a moderate density, a high past density, and an age profile dominated by older cohorts (Mallory et al., 1981; Boonstra, 1994). The low phase is characterized by a very

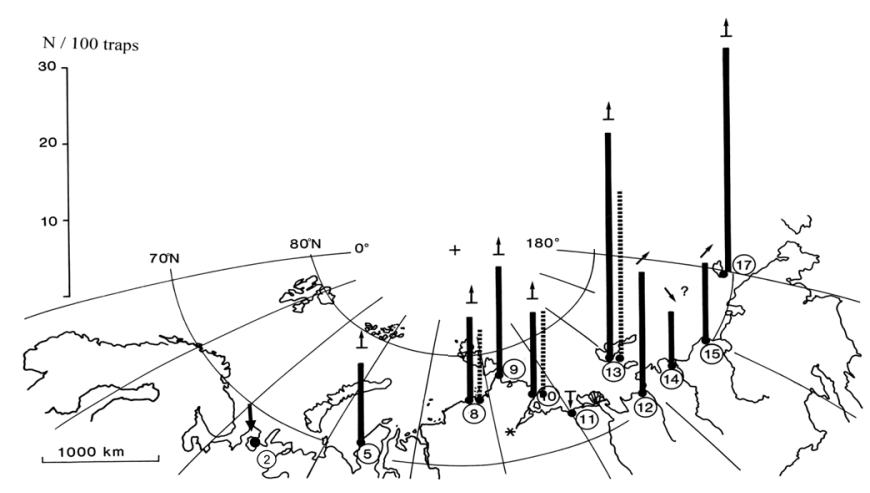

FIG. 1. Relative density of Siberian lemmings (number of captured individuals per 100 traps during $24 \mathrm{~h}$ ) at 12 sites along the Siberian tundra from the Kola Peninsula in the west to Wrangel Island in the east. Black bars denote densities measured when moving eastward in June and July, while striped bars show corresponding data collected on the return trip in July-August. On the New Siberian Islands (site 13), we worked at two different sites, Faddeyevskiy (black bar) on the way eastward and on Kotel'nyy, (striped bar) on the way back. Arrows above bars indicate the phases of the lemming cycle: whether the population at each site is increasing $(\gg)$, at peak $(\Uparrow)$, declining $(\Downarrow)$, or at its low phase $(\Downarrow)$. At site 11 , where the lemming population had recently crashed, we found an enormous amount of fresh lemming feces, but no lemmings were captured in the standardized trapping process. At site 2, where the population was also in low phase, no lemmings were captured either, but here almost no fresh feces were found.

low density and indications of a higher previous density. A crashed population has a very low density and clear signs of a recent very high density. Our phase determination generally agreed with results from Russian studies carried out at some of the same sites in the same year and in preceding and subsequent years (Tomkovich, 1998).

\section{Plant Sampling and Chemical Analysis}

Sedges (Carex ensifolia, C. stans, C. lugens) are important food plants for Siberian lemmings (Batzli, 1993). Two of these species, C. ensifolia and C. lugens, belong to the $C$. bigelowii complex. Carex ensifolia is distributed from the Kola Peninsula to the river Indigirka, and $C$. lugens, from Indigirka eastward into northern Canada (Jónsdóttir et al., 1995). Carex stans was studied at one site (Indigirka) where it occurred together with $C$. bigelowii-types. Samples of the two Carex species were not split. The inhibitors were based upon extracts from both species.

Twenty samples of green annual shoots of the clonal sedges were collected at each study site, within $50 \mathrm{~m}$ from the trap line. Samples were kept on ice in plastic containers, transferred to $-20^{\circ} \mathrm{C}$ within 24 hours, and stored until analysis. Samples were analyzed for proteinase inhibitor activity and protein content as described by Seldal et al. (1994). In short, finely chopped plant material was extracted $(1 \mathrm{~g}$ per $10 \mathrm{ml}$ of $40 \mathrm{mM}$ Tris- $\mathrm{HCl}$ buffer, $\mathrm{pH} 8.1$, containing $0.2 \%$ $(\mathrm{W} / \mathrm{v})$ Triton $\mathrm{x}-100)$ by homogenization at top speed for $2 \mathrm{~min}$. Soluble plant proteins (SPP) were measured by the protein-dye binding method (Bradford, 1976). The extracts were assayed for trypsin inhibitors (TI) in a standard assay on crystalline trypsin (125 units/assay) using N-p-toluenesulfonyl-L-arginine methyl ester as substrate (Bergmeyer 


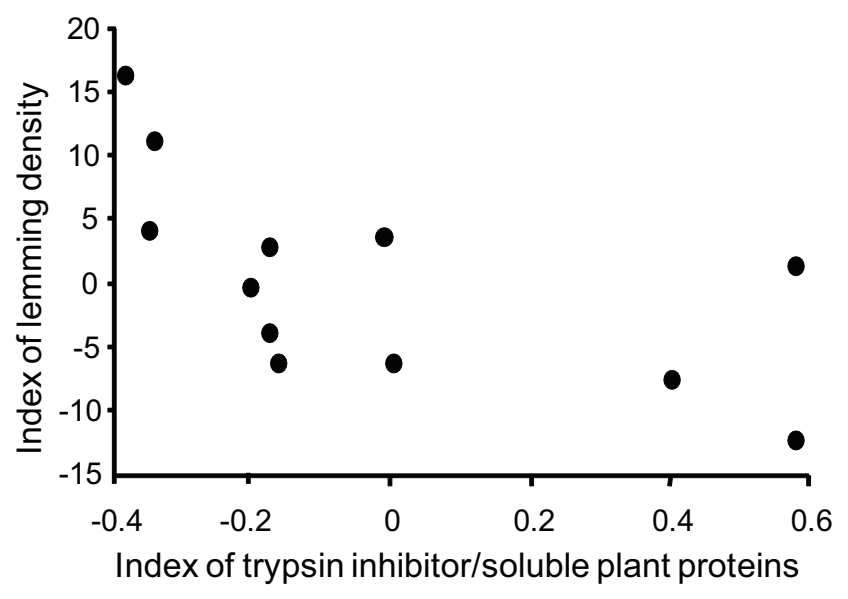

FIG. 2. Density of Siberian lemmings (number captured per 100 traps in 24 hours) in relation to trypsin inhibitor/soluble plant protein ratio (TI/SPP) in lemming food plants (Carex spp.) $(\mathrm{n}=12, \mathrm{r}=-0.62, p=0.03)$. Density and TI/ SPP data are residuals after having adjusted for seasonal effect.

and Gawehn, 1974). Hydrolysis of the ester was studied spectrophotometrically at $247 \mathrm{~mm}$ for $3 \mathrm{~min}$. Trypsin inhibition per minute was expressed as a percentage related to the standard assay activity containing equivalent amounts of extraction buffer. Differences in trypsin inhibitory activity between plant samples were calculated from the regression at $80 \mu \mathrm{g}$ protein/assay.

\section{Statistical Analyses}

We first adjusted the ratio of trypsin inhibitors to soluble plant proteins and the lemming density values for date effects by regressing TI/SPP and lemming density on date, and we then used the residuals from these regressions (hereafter called "index of TI/SPP" or "index of trypsin inhibitors/soluble plant protein" and "index of lemming density") for further analyses. Also, proportions were transformed (arcsin square root) before being analyzed using Pearson's product-moment correlation. For the eight main tests of the five specific predictions (see Introduction) that were based on population means from the 12 study sites, we used Pearson's correlations and one-tailed tests. For the auxiliary tests (pancreas mass and number of embryos per pregnant female) in which we could use individual lemmings as the dependent variable, we used backward stepwise multiple regressions, with the initial model including the independent factors index of density, locality, and index of TI/SPP. We then dropped nonsignificant factors until we reached a final model in which $p$ was less than 0.10 for all included independent factors.

\section{RESULTS}

\section{Lemming-Food Plant Interactions}

There was a significant negative correlation between the index of lemming density and the index of TI/SPP (Fig. 2).

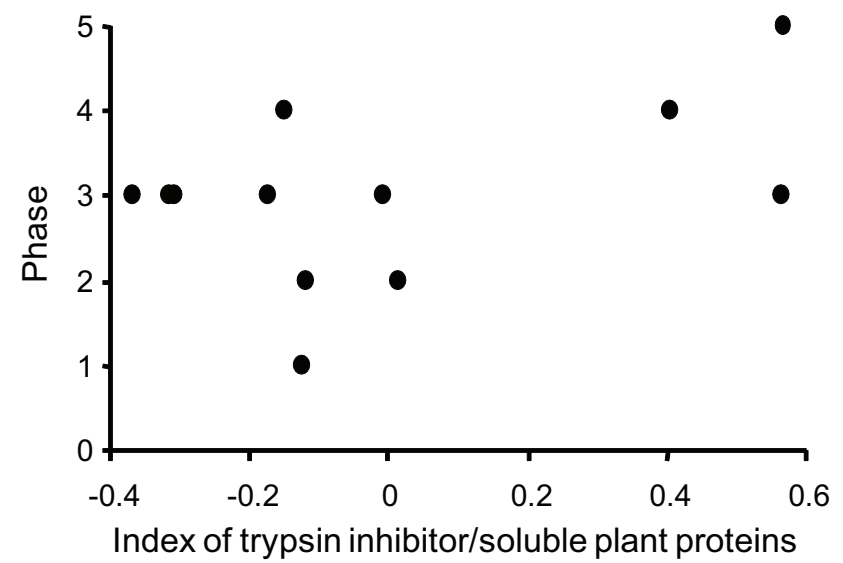

FIG. 3. Cycle phase in relation to the index of trypsin inhibitor/soluble plant protein (Spearman rank correlation: $\mathrm{r}_{\mathrm{s}}=0.46, p=0.07, \mathrm{n}=12$ ). $1=$ low phase, $2=$ Increase, 3 = Peak, $4=$ Decreasing, $5=$ Crashed.

Arranging the phases as in prediction 1 in the Introduction, we found a tendency toward a positive correlation between cycle phase and the index of TI/SPP (Fig. 3), but there was some deviation, especially for peak and decreasing populations.

Mean proportional size of pancreases obtained from freshly killed animals in six localities showed a weak tendency to correlate positively with the index of TI/SPP (Fig. 4). As we had data from only six localities, we also ran a stepwise multivariate analysis of all individual lemming samples from the six sites, with locality, index of density, and index of TI/SPP as possible independent variables. After dropping the nonsignificant variables locality ( $p=$ $0.80)$ and index of density $(p=0.86)$, we saw a highly significant positive relationship between pancreas size and the index of TI/SPP $(\mathrm{n}=37, \mathrm{r}=0.46, p=0.004)$.

Reproduction, measured as the proportion of females that were reproductively active (with embryos, lactating, or both), showed insignificant relationships with the index of TI/SPP for both young + subadult females $(\mathrm{n}=11, \mathrm{r}=0.44$, $p=0.11)$ and adult females $(\mathrm{n}=11, \mathrm{r}=0.27, p=0.22)$. Contrary to our prediction, the number of embryos per pregnant female in the different populations had a high positive correlation with the index of TI/SPP (Fig. 5).

There was a tendency for a negative relationship between the index of TI/SPP and the proportion of juvenile (age category 1 ) lemmings in the various populations $(\mathrm{n}=11, \mathrm{r}=$ $-0.48, p=0.07$ ), but when we excluded locality 11 , where no juvenile lemmings and three adults were live-trapped, the correlation was nonsignificant $(\mathrm{n}=10, \mathrm{r}=-0.34, p=0.17)$.

\section{Lemming Reproductive Activity and Density}

The proportion of adult females that were reproductively active tended to correlate negatively with the index of lemming density ( $\mathrm{n}=10, \mathrm{r}=-0.53, p=0.06)$, and for young + subadult females, this correlation was highly significant $(\mathrm{n}=10, \mathrm{r}=-0.76, p=0.005)$ (Fig. 6). 


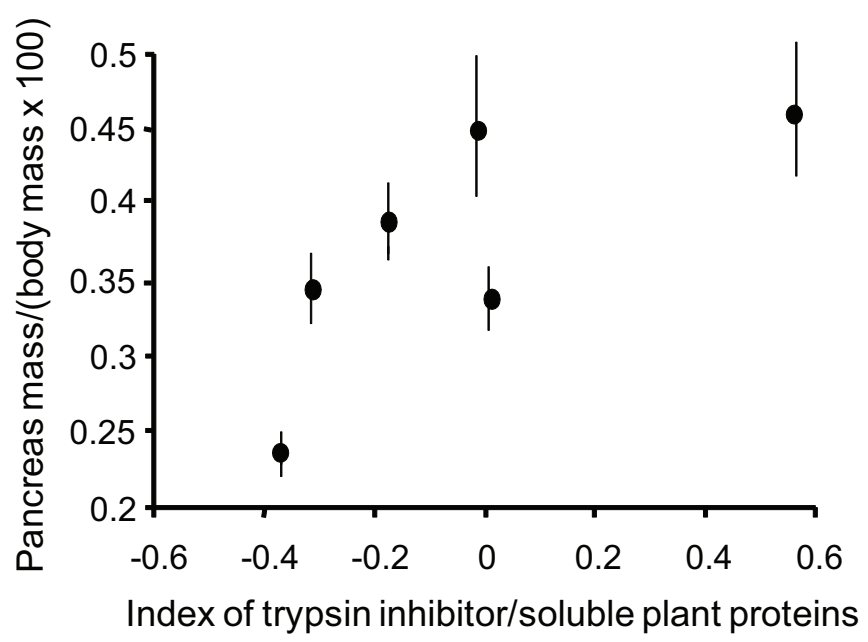

FIG. 4. Proportional mass of pancreas (pancreas mass/body mass $\times 100$ ) in relation to the index of trypsin inhibitor/soluble plant protein. Mean value $\pm \mathrm{SE}=\{$ (pancreas/body mass) $\times 100\} /$ Index of TI/SPP for each locality is given $(\mathrm{n}=6, \mathrm{r}=0.74, p=0.09)$.

Furthermore, the number of embryos per pregnant female also correlated negatively with the index of lemming density (Fig. 7). To analyze this correlation further on an individual basis and also investigate for effects of TI content, we performed multivariate analysis on all individual pregnant females (data from 10 sites), with number of embryos as the dependent variable and index of density, locality, and index of TI/SPP as possible independent variables. After dropping the nonsignificant variable index of TI/SPP $(p=0.22)$, we found a significant negative relationship between the number of embryos and density ( $\mathrm{n}=75, p=0.002)$ when locality $(p=0.028)$ was also included in the model.

\section{DISCUSSION}

Data for cyclic phase and pancreas mass were largely in accordance with our predictions from the plant-defence hypothesis, thus supporting predictions 1 and 2. However, other analyses did not support this hypothesis. In particular, data on reproductive effort conflict with the predictions of the plant-defence hypothesis (prediction 3), but agree with the self-regulating hypothesis (prediction 5). How can these findings be reconciled? One possible scenario is that TI/SPP primarily affects recruitment of juveniles, and thereby lemming density, which in turn determines reproductive output. At high densities, only the most competitive (oldest) females reproduce (Erlinge et al., 2000), and their reproduction seems to be less affected by TI/SPP than that of younger females, possibly because they can settle in the best parts of the habitat, containing the highest-quality pasture and the best shelter from predators. This pattern suggests a scenario in which predation interacts with food quality, explaining the observed correlations. Clearly, the risk of being caught by predators shapes the foraging habits of lemmings, as is seen from their concentrated grazing close to runways and shelters (Fig. 8). Berg (2003), who

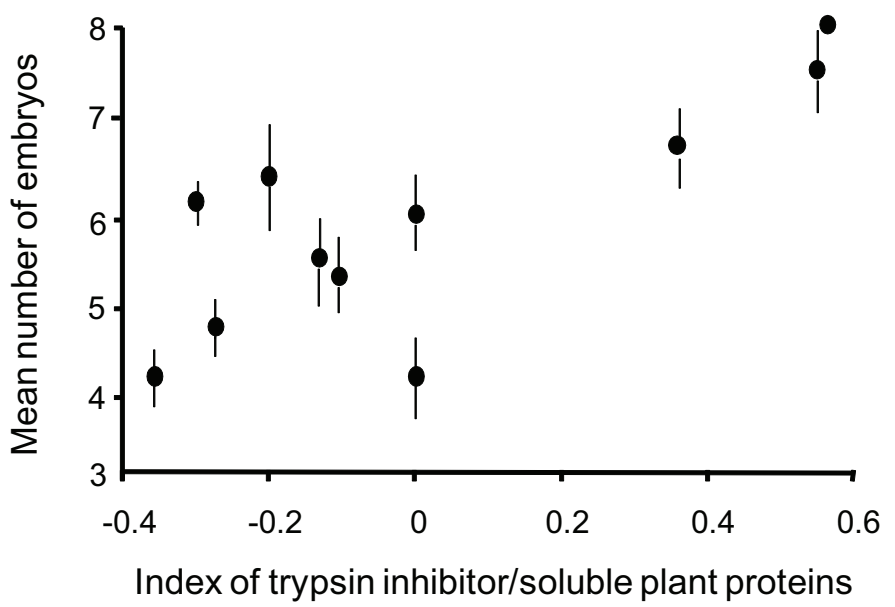

FIG. 5. Mean number of embryos per pregnant female \pm SE for each locality in relation to the index of trypsin inhibitor/soluble plant protein $(\mathrm{n}=11, \mathrm{r}=$ $0.72, p=0.005)$.

studied collared lemming foraging behavior in Greenland, made similar observations.

The index of TI/SPP tended to correlate positively with cycle phase (Fig. 3), suggesting a delayed effect of TI/SPP. There was some uncertainty about classification of the cycle phase for four localities, but any alternative combination of classifications in Figure 3 changed the correlation only marginally ( $\mathrm{r}$ between 0.47 and 0.53 ). The classification given in Figure 3 is the most conservative. The response of the different Carex forms did not show any consistent difference, but all of them seem to follow the variation in smallrodent density. The fairly weak correlation between TI/SPP in food plants and the phase of the lemming cycle was connected with a large variation in inhibition at the peak phase sites. It might be that peak phase populations were in different stages, i.e., in the early or the late stage of the peak phase, or grazing pressure on the sedges could have varied with the strength of the stimulus for induction of defence compounds. This variation could have an influence on the proteinase inhibitor contents of the food plants.

We found a significant negative correlation between the index of TI/SPP and lemming density at the 12 study sites (prediction 1 in the Introduction). The low level of the index of TI/SPP in the plants of the populations showing peak lemming density suggests that grazing has a delayed effect on the induction of trypsin inhibitors in the food plants, which is in line with predictions from the induced plant defence hypothesis. Hence, the negative correlation in Figure 2 can be interpreted as compatible with the plant defence hypothesis, if the high level of trypsin in the food measured at medium- and low-density lemming sites was the cause for the population decline. However, we must keep in mind that the causal relationship cannot be determined from this correlation.

Pancreatic hypertrophy is a consequence of reduction of proteolytic enzymes in response to exposure to TI. Pancreatic mass is considered hypertrophic when it exceeds $0.3 \%$ of the body mass (Gallaher and Schneeman, 1986). 


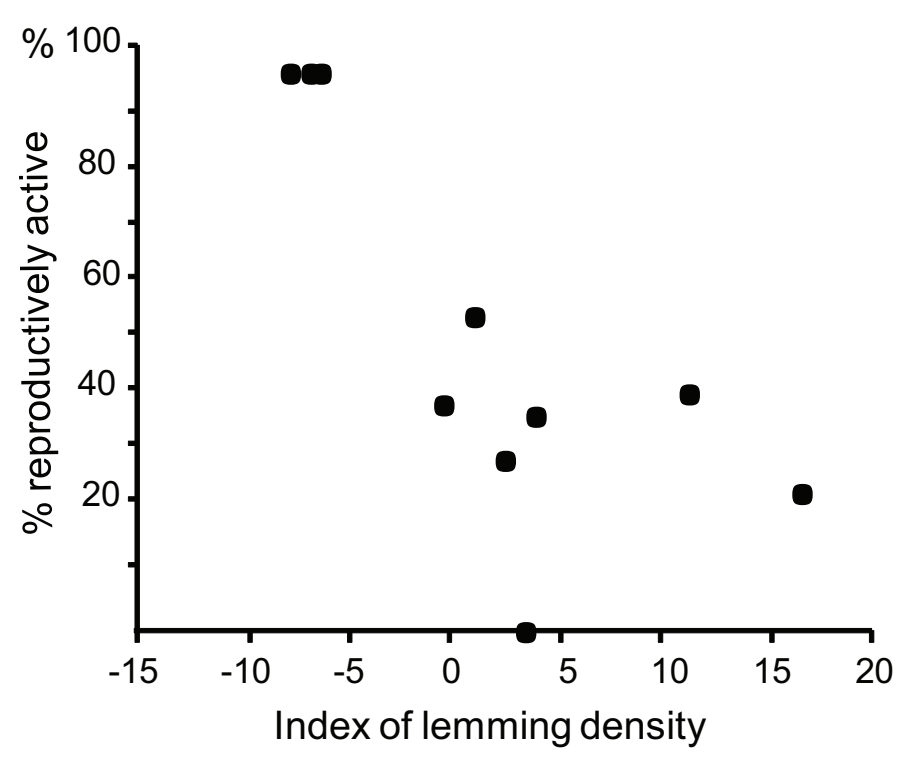

FIG. 6. Proportion of young (less than 1 year old) females reproductively active (lactating or pregnant or both) in relation to the index of lemming density $(\mathrm{n}=10, \mathrm{r}=-0.76, p=0.005$. For statistical calculations, proportions were arcsin square root transformed before being included in the Pearson's correlation.

We found a significant correlation between mean pancreas size and the index of TI/SPP based on individual level data. There was considerable variation between individuals; they might have reacted differently to TI, or experienced varying degrees of exposure.

The demographic variables show a complicated picture, at times contradicting the predictions of the plant-defence hypothesis. The proportion of juveniles (range $0-20 \%$ ) showed only a tendency to correlate with the index of TI/ SPP, and the overall age profile (based on eye-lens mass) was not correlated with TI/SPP in the predicted direction. Neither the proportion of juveniles nor the age profile was correlated with lemming density. Although not conclusive, these data might indicate that TI/SPP can have a direct negative effect on recruitment of juveniles, possibly via a lowered survival rate.

Considering reproductive effort, the proportion of young and subadult females showed positive but nonsignificant correlations with the index of TI/SPP. The number of embryos per pregnant female, however, showed a significant positive correlation with the index of TI/SPP. These findings are opposite to predictions of the plant-defence hypothesis if high TI levels have a direct negative influence on female reproduction. Klemola et al. (2000b) did not find any detrimental effects of previous grazing on reproduction in cyclic voles in Finland. An alternative interpretation of these results could be that the microtines can detect that they are exposed to food of poor quality and therefore invest more in breeding as a means of terminal investment. Laboratory studies showed that parasitic infection increased reproductive output in deer mice (Schwanz, 2008).

We found that density had a significant negative influence on the reproductive activity of young female

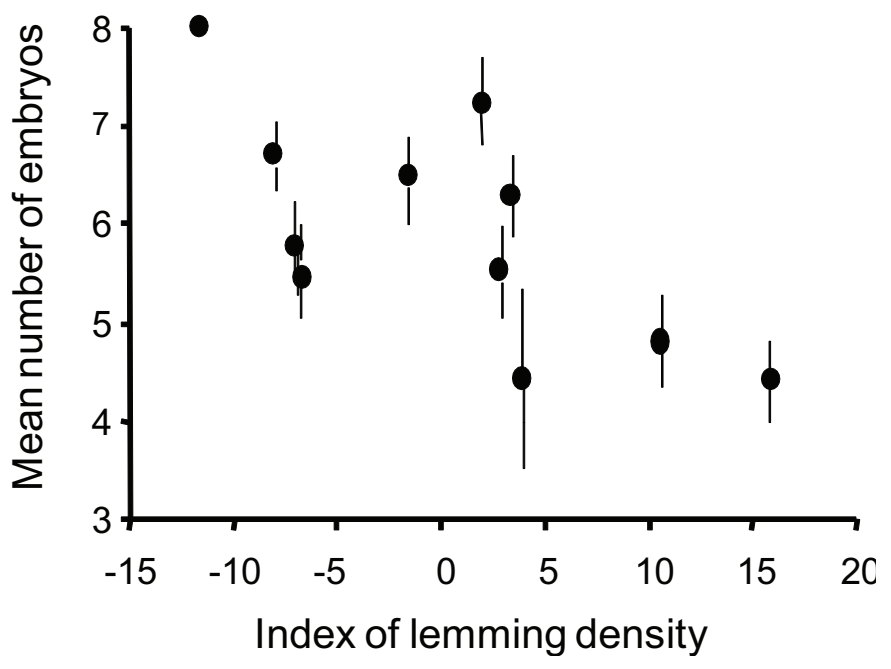

FIG. 7. Mean number of embryos per pregnant female $\pm \mathrm{SE}$ in relation to the index of lemming density $(\mathrm{n}=11, \mathrm{r}=-0.66 . p<0.013)$.

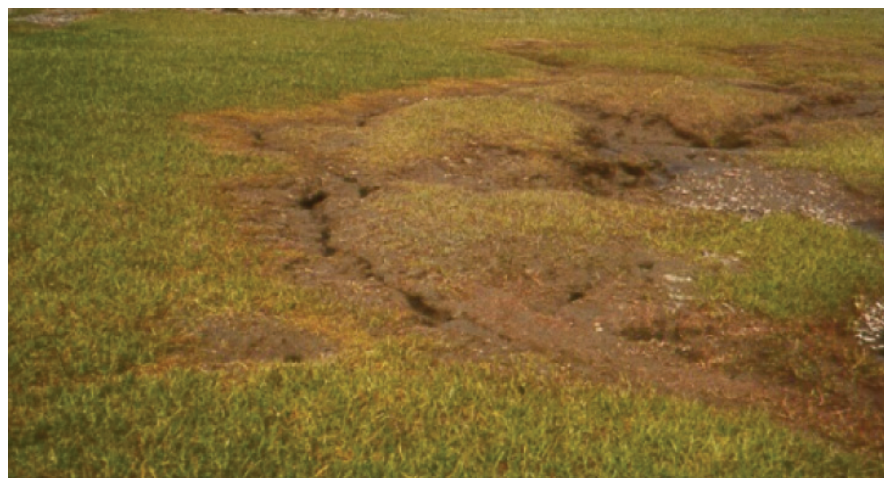

FIG. 8. Lemmings at Kotel'nyy, New Siberian Islands, forage close to runways and shelters, primarily tunnels in grasslands and heap of stones, to reduce the risk of predation. Lemming density was high (22 captured lemmings) at this site, and the population was considered to be in peak phase, probably close to decrease. Photo taken on 30 July 1994.

lemmings, but only a tendency toward such a relationship in adult females. For all pregnant females, the number of embryos was negatively affected by lemming density. With respect to reproductive effort, several factors might interact; however, our data suggest that lemming density may overshadow the effects of food quality. The number of embryos per pregnant female had not only a negative correlation with density, but also a surprisingly positive correlation with TI/SPP. Presumably, intra-specific competition is an important element of such a density effect, having its greatest negative impact on younger females (age categories 1 and 2) (see also Erlinge et al., 2000). Social constraints have been implicated in other populations, for example, as a factor affecting maturation in bank voles, Clethrionomys glareolus (Prevot-Julliard et al., 1999).

We do not know if density has a delayed effect on the lemmings' reproductive activity and so could act as a driving force for cyclic dynamics. Females in increasing populations start to reproduce at an early age (Erlinge et al., 2000), which could be a delayed effect due to favourable conditions for young females when growing up. The early 
start in increasing populations, however, could be due to low risk of predation and low content of chemical defence at that time.

In conclusion, our data suggest that the cyclic dynamics of Siberian lemmings are caused by a combination of delayed trophic interactions and density-dependent reproductive efforts. This idea supports the suggestion from modeling that, in addition to trophic interaction generating cyclic dynamics, some self-regulation must occur to structure the available time series (Stenseth et al., 1996). Also, our data agree with the suggestion of Krebs (2009) that for small herbivorous mammals with altricial young, population control is determined by a combination of top-down, bottom-up, and intrinsic mechanisms. Hence, our study implies that single-factor hypotheses are often inadequate to explain cyclic dynamics in small rodents. Instead, multifactor models are more likely to explain these patterns.

\section{ACKNOWLEDGEMENTS}

The Swedish Polar Secretariat organized the Swedish-Russian Tundra Expedition 94 and provided excellent logistics. The Norwegian and Swedish Research Councils funded the collection and analysis of the data, and the Royal Physiographic Society in Lund provided financial support to S. Erlinge. We are grateful to $\mathrm{V}$. Federov for providing data on the pancreas in lemmings, to B. Gharehnia for chemical analysis of the plants, to P. Nilsson for taking part in the fieldwork, and to Andreas Nord for technical assistance. We thank three reviewers for valuable comments on the manuscript.

\section{REFERENCES}

Angerbjörn, A., Tannerfeldt, M., and Erlinge, S. 1999. Predatorprey relationships: Arctic foxes and lemmings. Journal of Animal Ecology 68:34-49.

Batzli, G.O. 1993. Food selection by lemmings. In: Stenseth, N.C., and Ims, R.A., eds. The biology of lemmings. London: Academic Press. 281-301.

. 1996. Population cycles revisited. Trends in Ecology and Evolution 11:488-489.

Berg, T.B. 2003. The collared lemming (Dicrostonyx groenlandicus) in Greenland: Population dynamics and habitat selection in relation to food quality. $\mathrm{PhD}$ thesis, University of Copenhagen.

Bergmeyer, H.U., and Gawehn, K. 1974. Methods of enzymatic analysis. New York: Academic Press.

Boonstra, R. 1994. Population cycles in microtines: The senescence hypothesis. Evolutionary Ecology 8:196-219.

Bradford, M. 1976. A rapid and sensitive method for quantitation of microgram quantities of protein utilizing the protein-dye binding. Analytical Biochemistry 72:248-254.

Chernyavskii, F.B., and Tkachev, A.V. 1982. Population cycles of lemmings in the Arctic (in Russian). Moscow: Nauka.
Danell, K., Ericson, L., and Jakobsson, K. 1981. A method for describing former fluctuations of voles. The Journal of Wildlife Management 45:1018-1021.

Danell, K., Roininen, H., Olofsson, E.B., Ericson, L., and Palo, T. 1995. Interactions between willows and herbivores. In: Grönlund, E., and Melander, O., eds. Swedish-Russian Tundra Ecology-Expedition 1994: A cruise report. Stockholm: Swedish Polar Research Secretariat. 49-55.

Danell, K., Erlinge, S., Högstedt, G., Hasselquist, D., Olofsson, E.-B., Seldal, T., and Svensson, M. 1999. Tracking past and ongoing lemming cycles on the Eurasian tundra. Ambio 28:225-229.

Erlinge, S., Danell, K., Frodin, P., Hasselquist, D., Nilsson, P., Olofsson, E.-B., and Svensson, M. 1999. Asynchronous population dynamics of Siberian lemmings across the Palaearctic tundra. Oecologia 119:493-500.

Erlinge, S., Hasselquist, D., Svensson, M., Frodin, P., and Nilsson, P. 2000. Reproductive behaviour of female Siberian lemmings during the increase and peak phase of the lemming cycle. Oecologia 123:200-207.

Gallaher, D., and Schneeman, B.O. 1986. Nutritional and metabolic response to plant inhibitors of digestive enzymes. Advances in Experimental and Medical Biology 199:167-184.

Gilg, O., Hanski, I., and Sittler, B. 2003. Cyclic dynamics in a simple vertebrate predator-prey community. Science 302: $866-868$.

Graham, I.M., and Lambin, X. 2002. The impact of weasel predation on cyclic field-vole survival: The specialist predator hypothesis contradicted. Journal of Animal Ecology 71: 946-956.

Hörnfeldt, B. 1994. Delayed density dependence as a determinant of vole cycles. Ecology 75(3):791 - 806.

- 2004. Long-term decline in numbers of cyclic voles in boreal Sweden: Analysis and presentation of hypotheses. Oikos 107(2):376-392.

Jonasson, S., Bryant, J.P., Chapin, F.S., III, and Andersson, M. 1986. Plant phenols and nutrients in relation to variations in climate and rodent grazing. The American Naturalist 128: 394-408.

Jónsdóttir, I.S., Fagerström, T., Augner, M., and Lindskog, A. 1995. Variation in the population dynamics and local adaptations of some plant species along a circumpolar sector in relation to the population size of potential herbivores and climate. In: Grönlund, E., and Melander, O., eds. SwedishRussian Tundra Ecology-Expedition 1994: A cruise report. Stockholm: Swedish Polar Research Secretariat. 68-76.

Karban, R., and Baldwin, I.T. 1997. Induced responses to herbivory. Chicago: University of Chicago Press.

Klemola, T., Koivula, M., Korpimäki, E., and Norrdahl, K. 2000a. Experimental tests of predation and food hypotheses for population cycles of voles. Proceedings of the Royal Society of London, Series B 267:351-356.

Klemola, T., Norrdahl, K., and Korpimäki, E. 2000b. Do delayed effects of overgrazing explain population cycles in voles? Oikos 90:509-516. 
Korpimäki, E., and Norrdahl, K. 1998. Experimental reduction of predators reverses the crash phase of small-rodent cycles. Ecology 79:2448-2455.

Korpimäki, E., Norrdahl, K., Klemola, T., Pettersen, T., and Stenseth, N.C. 2002. Dynamic effects of predators on cyclic voles: Field experimentation and model extrapolation. Proceedings of the Royal Society of London, Series B 269: 991- 997.

Krebs, C.J. 2009. Population dynamics of large and small mammals: Graeme Caughley's grand vision. Wildlife Research $36: 1-7$.

- 2011. Of lemmings and snowshoe hares: The ecology of northern Canada. Proceedings of the Royal Society of London, Series B 278:481-489.

Krebs, C.J., and Myers, J.H. 1974. Population cycles in small mammals. Advances in Ecological Research 8:267-399.

Krebs, C.J., Danell, K., Angerbjörn, A., Agrell, J., Berteaux, D., Bråthen, K.A., Danell, Ö., et al. 2003. Terrestrial trophic dynamics in the Canadian Arctic. Canadian Journal of Zoology 81:827-843.

Laine, K.M., and Henttonen, H. 1987. Phenolics/nitrogen ratios in the blueberry Vaccinium myrtillus in relation to temperature and microtine density in Finnish Lapland. Oikos 50:389-395.

Lindroth, R.L., and Batzli, G.O. 1986. Inducible plant chemical defences: A cause of vole population cycles? Journal of Animal Ecology 55:431-449.

Mallory, F.F., Elliott, J.R., and Brooks, R.J. 1981. Changes in body size in fluctuating populations of the collared lemming: Age and photoperiod influences. Canadian Journal of Zoology 59:174-182.

Myllymäki, A., Paasikallio, A., Pankakoski, E., and Kanervo, V. 1971. Removal experiments on small quadrats as a means of rapid assessment of the abundance of small mammals. Annales Zoologici Fennici 8:177-185.
Oksanen, L., Oksanen, T., Lukkari, A., and Sirén, S. 1987. The role of phenol-based inducible defense in the interaction between tundra populations of the vole Clethrionomys rufocanus and the dwarf shrub Vaccinium myrtillus. Oikos 50:371-380.

Prévot-Julliard, A.-C., Henttonen, H., Yoccoz, N.G., and Stenseth, N.C. 1999. Delayed maturation in female bank voles: Optimal decision or social constraint? Journal of Animal Ecology 68:684-697.

Schwanz, L.E. 2008. Chronic parasitic infection alters reproductive output in deer mice. Behavioral Ecology and Sociobiology 62:1351-1358.

Seldal, T. 1994. Proteinase inhibitors in plants and fluctuating populations of herbivores. PhD dissertation, Bergen University, Norway.

Seldal, T., Andersen, K.J., and Högstedt, G. 1994. Grazinginduced proteinase inhibitors: A possible cause for lemming population cycles. Oikos 70:3-11.

Stenseth, N.C., and Ims, R.A. 1993. Population dynamics of lemmings: Temporal and spatial variation - an introduction. In: Stenseth, N.C., and Ims, R.A., eds. The biology of lemmings. London: Academic Press. 61-96.

Stenseth, N.C., Bjornstad, O.N., and Falck, W. 1996. Is spacing behaviour coupled with predation causing the microtine density cycle? A synthesis of current process-oriented and pattern-oriented studies. Proceedings of the Royal Society of London, Series B 263:1423-1435.

Sundell, J. 2002. Population dynamics of microtine rodents: An experimental test of the predation hypothesis. Oikos 101: 416-427.

Tomkovich, P.S. 1998. Breeding conditions for waders in Russian tundras in 1994. International Wader Studies 10:132-144. (Reprinted with corrections from Wader Study Group Bulletin 79:71-81.)

Turchin, P., and Batzli, G.O. 2001. Availablity of food and the population dynamics of arvicoline rodents. Ecology 82: $1521-1534$. 